\title{
PESQUISAS REALIZADAS PELO PRÓ-SAÚDE GEO ENTRE 2010 E 2020 NA ÁREA DE METODOLOGIA DA PESQUISA E ENSINO: TEORIAS, GRUPOS DE PESQUISA E TRABALHO DE CAMPO
}

\section{SURVEYS CARRIED OUT BY PRO-SAÚDE GEO BETWEEN 2010 AND 2020 IN THE AREA OF RESEARCH AND TEACHING METHODOLOGY: THEORIES, RESEARCH GROUPS AND FIELD WORK}

\author{
Martha Priscila Bezerra Pereira \\ Universidade Federal de Campina Grande, Campina Grande, PB, Brasil \\ mpbcila@yahoo.com.br
}

\begin{abstract}
RESUMO
Este texto trata de uma síntese dos trabalhos de pesquisa de Iniciação Científica realizada pelo Grupo de Pesquisa Pró-Saúde Geo entre 2010 e 2020 e suas aplicabilidades na graduação em Geografia da UFCG - campus Campina Grande, Paraíba, Brasil. Desta forma, tem como objetivo fazer uma síntese das pesquisas realizadas entre 2010 e 2020 relacionadas a linha "Metodologia da Pesquisa e ensino" pelo grupo de Pesquisa em Geografia para promoção da saúde. Para viabilizar esta síntese optou-se pelos seguintes procedimentos: a) levantamento de referências; b) análise de pesquisas de iniciação científica realizadas entre 2010 e 2020 na linha de pesquisa "Metodologia da pesquisa e ensino" e; c) levantamento documental. Como principais resultados para o grupo de pesquisa percebeu-se que essas pesquisas trouxeram uma maior dinâmica no uso de teorias, de opções metodológicas e em relação a organização de um trabalho de campo melhor planejado. Para as disciplinas houve uma melhoria na qualidade de seu conteúdo teórico e viabilizou maior qualidade na relação teórico-prática, principalmente na execução de trabalhos de campo. Em síntese, essas pesquisas, inicialmente básicas, apresentaram aplicabilidades tanto para o ensino quanto para o próprio grupo de pesquisa e potencialmente serve de base para projetos de extensão.
\end{abstract}

Palavras-chave: Pesquisa. Metodologia. Iniciação Científica.

\begin{abstract}
This text is a synthesis of Scientific Initiation research works carried out by the Pró-Saúde Geo Research Group between 2010 and 2020 and their applicability in the undergraduate course in Geography at UFCG - Campina Grande campus, Paraiba, Brazil. Thus, it aims to make a synthesis of research carried out between 2010 and 2020 related to the line "Research and teaching methodology" by the group of Research in Geography for health promotion. To make this synthesis viable, the following procedures were chosen: a) survey of references; b) analysis of scientific initiation research carried out between 2010 and 2020 in the research line "Research and teaching methodology" and; c) documentary survey. As main results for the research group, it was noticed that these researches brought a greater dynamic in the use of theories, methodological options and in relation to the organization of a better planned field work. For the disciplines, there was an improvement in the quality of their theoretical content and enabled greater quality in the theoretical-practical relationship, especially in the execution of fieldwork. In summary, these initially basic researches had applicability both for teaching and for the research group itself and potentially serves as a basis for extension projects.
\end{abstract}

Keywords: Search. Methodology. Scientific research.

\section{INTRODUÇÃO}

Este texto trata de uma síntese dos trabalhos de pesquisa realizados pelo grupo de Pesquisa Pró-Saúde Geo na linha de pesquisa "Metodologia da pesquisa e ensino" e a aplicação desses resultados no ensino da graduação entre 2010 e 2020 no âmbito do curso de Geografia da UFCG, no campus de Campina Grande - PB. Este trabalho foi aprovado no eixo "Dimensões históricas, teóricas e metodológicas da Geografia da Saúde" no âmbito do X Simpósio Nacional de Geografia da Saúde e selecionado para

Recebido em: 15/01/2022

Aceito para publicação em: 27/01/2022.

Hygeia Uberlândia - MG $\quad$ Edição especial: X GeoSaude $\quad$ Fev./2022 p. 136-154 Página 136


publicação neste periódico. Quanto a classificação geral de pesquisas, estas estariam inseridas nas ciências humanas, são pesquisas básicas e variam entre exploratórias e descritivas (GIL, 2010).

O Pró-Saúde Geo, ou Grupo de Pesquisa em Geografia para Promoção da Saúde tem como principal objetivo elaborar projetos em caráter transdisciplinar na área de Políticas Públicas e Saúde Ambiental aproximando o conhecimento geográfico com a saúde coletiva (PRÓ-SAÚDE GEO, 2021).

Ao longo de sua existência (2010-2021), tem elaborado trabalhos em quatro linhas de pesquisa: a) a arte de cuidar da saúde; b) metodologia da pesquisa e ensino; c) Políticas Públicas voltadas à saúde e; d) Território, ambiente e saúde.

Este trabalho teve como objetivo fazer uma síntese das pesquisas realizadas entre 2010 e 2020 relacionadas com a linha "Metodologia da pesquisa e ensino" pelo grupo de Pesquisa em Geografia para a Promoção da Saúde. Foram relacionados apenas os trabalhos dessa linha de pesquisa que foram aprovados pelo Programa Institucional de Bolsas de Iniciação Científica (PIBIC) e Programa Institucional de Voluntários de Iniciação Científica (PIVIC).

Este texto está dividido em sete partes, além desta introdução e das considerações finais. Na primeira parte "Metodologia" foram apresentados os procedimentos práticos seguidos, assim como foram apontados os autores utilizados como fundamento teórico-metodológico desta publicação. Na "Fundamentação teórica" busca-se justificar a classificação desses estudos nessa linha de pesquisa do grupo Pró-Saúde Geo e ao mesmo tempo esclarece-se que em cada etapa de pesquisa há escolhas definidas por filtros, seja pelos sujeitos pesquisadores (professor/aluno) ou pelos sujeitos pesquisados. Na parte da "Escolha das pesquisas a serem analisadas" foram apresentadas todas as pesquisas da linha Metodologia da pesquisa e ensino do período entre 2010 e 2020, sendo realizado um recorte para este artigo apenas relacionando as pesquisas que tem vínculo com a Geografia da Saúde. Em relação ao item "Pesquisa sobre Teorias" foi apresentado o entendimento da autora sobre o conceito de teoria, baseado nas características das teorias apresentadas por vários autores e em seguida as teorias escolhidas para serem analisadas nessa pesquisa de iniciação científica. No item "Pesquisa sobre Grupos de Pesquisa em Geografia da Saúde e correlacionados" apresentou-se os grupos de pesquisa na área de Geografia da Saúde e correlatos que foram organizados e que foram divulgados de alguma maneira nas redes sociais ou plataformas de busca. A partir dessa identificação foi realizada uma hierarquização com base nas redes formadas e posteriormente situou-se o Pró-Saúde Geo nesse contexto. As "Pesquisas sobre Trabalho de Campo" enfatizaram os elementos observados para se classificar o tipo de paisagem (risco, prevenção, cura, promoção) de cada local indicado como de interesse para a Geografia da Saúde. O item "Aplicabilidades" tratou de organizar e exemplificar como essas pesquisas foram úteis em sala de aula, nas pesquisas do próprio Pró-Saúde Geo, assim como há possibilidade de uso desses resultados para extensão.

\section{METODOLOGIA}

Para viabilizar esta síntese, optou-se pelos seguintes procedimentos: a) levantamento de referências; b) análise de pesquisas de iniciação científica realizadas entre 2010 e 2020 na linha de pesquisa "Metodologia da pesquisa e ensino" e; c) levantamento documental.

O levantamento de referências foi realizado para aprofundar um pouco mais sobre os procedimentos metodológicos e a fundamentação teórica.

Em relação às referências relacionadas ao procedimento metodológico trabalhou-se com a análise comparativa (CERVO, BERVIAN \& SILVA, 2007; MARCONI \& LAKATOS, 2010) e pesquisa bibliográfica (CERVO, BERVIAN \& SILVA, 2007; GIL, 2010; MARCONI \& LAKATOS, 2010; SEVERINO, 2016).

No que diz respeito às referências relacionadas à fundamentação teórica foram melhor trabalhados textos sobre delineamentos (GIL, 2010); métodos de procedimento (CERVO, BERVIAN \& SILVA, 2007; CHIZZOTTI, 2011; GIL, 2010; MARCONI \& LAKATOS, 2010; SEVERINO, 2016), cosmovisão (DEMO, 2014; NAUGLE, 2017, SIRE, 2018), intencionalidade (SEARLE, 2002), autonomia (CASTORIADIS, 1990; SOUZA, 2006; CASTORIADIS,2007) e escala de observação (CASTRO, 1995; LACOSTE, 1997; SOUZA, 2015).

A análise das pesquisas foi realizada evidenciando a questão metodológica e suas possibilidades de aplicabilidade reais e potenciais em disciplinas, em outras pesquisas e até mesmo possivelmente na extensão, além de destacar as que abrangeram o município de Campina Grande - PB, Brasil.

O levantamento documental foi realizado a partir dos relatórios de pesquisa. Foram ao todo cinco pesquisas pelo Programa Institucional de Voluntários de Iniciação Científica (PIVIC) e duas pesquisas pelo Programa Institucional de Bolsas de Iniciação Científica (PIBIC).

\begin{tabular}{llllll}
\hline Hygeia Uberlândia - MG & Edição especial: X GeoSaude & Fev./2022 & p. 136-154 & Página 137
\end{tabular}




\section{FUNDAMENTAÇÃO TEÓRICA}

As pesquisas escolhidas destacaram-se por evidenciar delineamentos (GIL, 2010) e métodos de procedimento (MARCONI \& LAKATOS, 2010).

Com base em autores como Cervo, Bervian e Silva (2007), Marconi e Lakatos (2010), Gil (2010) e Chizzotti (2011) os delineamentos e métodos de procedimento variam conforme a fundamentação teórica, quantidade de locais ou instituições estudadas, quanto ao ambiente em que são coletados, quanto ao envolvimento dos sujeitos pesquisados e quanto ao grau de controle de variáveis. Devido a essa variedade de classificações é que se tem a possibilidade de utilizar vários métodos ao mesmo tempo em uma única pesquisa e utilizar vários tipos de pesquisa, assim como não necessariamente se utiliza de todos esses critérios ao mesmo tempo.

Os delineamentos seriam o planejamento de pesquisa em uma dimensão ampla, que envolve os fundamentos teórico-metodológicos, objetivos, ambiente da pesquisa, técnicas de coleta, análise de dados, entre outras possibilidades. Esse delineamento expressaria a ideia de um modelo, de um plano geral a ser seguido (GIL, 2010).

Os métodos de procedimento têm relação com etapas menos abstratas da pesquisa, mas que igualmente delineiam as ações do pesquisador durante o processo de execução de pesquisa (MARCONI \& LAKATOS, 2010).

$\mathrm{Na}$ fundamentação teórica estão implícitas muitas interferências, dentre elas pode-se citar a cosmovisão, a intencionalidade, a autonomia, e a escala de observação do sujeito pesquisador que influenciam na maneira como são delineados ou escolhidos os paradigmas, métodos científicos, teorias, termos, conceitos e definições.

A cosmovisão, termo utilizado pela primeira vez por Immanuel Kant como "weltanchauung", ou seja, "nossa intuição do mundo" (NAUGLE, 2017), passou a ser entendida na atualidade como uma maneira particular de ver as coisas (DEMO, 2014), como uma orientação que se expressa como o fundamento sobre o qual nos movemos, vivemos e existimos (SIRE, 2018).

Essa orientação básica de nossa cosmovisão está embutida em nosso subconsciente. Está em nossa mente de forma tão profunda que na maioria das vezes nem percebemos, mas ela se expressa através de nossas palavras e ações (SIRE, 2018), sempre que estamos livres para manifestá-la.

A intencionalidade entendida aqui como uma atividade mental dirigida a objetos ou estado de coisas no mundo (SEARLE, 2002) contribui para a materialização da cosmovisão.

Havendo a liberdade para falar e agir aproxima-se do conceito de autonomia, trabalhado por Castoriadis $(1990 ; 2007)$ como se referindo a capacidade de autogestão individualmente ou coletivamente. A palavra autonomia se origina do grego autós (o próprio), mais nómos, que possui duas acepções: 'lei' e convenção' (SOUZA, 2006). Pode ser entendida como lei própria, ou convenção própria. Quando essa autonomia se expressa individualmente, pode-se entender que há o domínio do consciente sobre o inconsciente, em que o sujeito se autogoverna, tem um discurso, um pensamento próprio. Quando a autonomia se expressa coletivamente afirma-se que há um autogoverno da coletividade. Desta forma, pode-se entender que esse seria o discurso do outro, ou a síntese do discurso de determinado grupo.

A partir desses dois tipos de autonomia (individual e coletiva) trabalhados pelos autores supracitados podese pensar em dois tipos consequentes de autonomia, a autonomia teórica (que é exercida no pensamento do sujeito individualmente, que pode ou não ser colocado em prática) e a autonomia prática (quando a autonomia individual pode ser efetivada na coletividade, quando o seu discurso individual prevalece). Essa autonomia prática depende das características pessoais e do contexto vivenciado em um momento histórico específico, seja na ciência, a depender de determinada escola do pensamento científico que esteja mais ou menos fortalecida, do contexto político, entre outras possibilidades de influências.

Enfim, a nossa cosmovisão, que gera intencionalidades, só será manifesta se houver autonomia prática, seja ela individual (quando o sujeito se conhece o suficiente para saber o que pensa e como pensa, sendo capaz de agir de forma coerente com sua cosmovisão) ou coletiva (em que seu pensamento e ação é capaz de influenciar outras pessoas e prevalecendo a partir de um projeto coletivo). A cosmovisão e a intencionalidade, associadas a autonomia prática (individual ou coletiva) é que influenciam na escolha de paradigmas, métodos científicos, teorias, termos, conceitos e definições.

\begin{tabular}{llllll}
\hline Hygeia & Uberlândia - MG $\quad$ Edição especial: X GeoSaude & Fev./2022 & p. 136-154 & Página 138
\end{tabular}


Em outras palavras, um mesmo fato pode ser observado a partir de variadas maneiras, a depender de sua cosmovisão, das intencionalidades e a partir do grau de sua autonomia pode ser expresso de maneira coerente a sua cosmovisão.

Além da cosmovisão, das intencionalidades e da autonomia, a escala de observação também pode influenciar na maneira como se observa determinado fato, e ela geralmente estaria relacionada a uma ciência ou uma área de determinada ciência (LACOSTE, 1997; CASTRO, 1995; SOUZA, 2015). Um exemplo pode ser apresentado a partir da pandemia da Covid-19 em que as mais variadas ciências observaram o mesmo fato a partir de um aspecto diferenciado e a partir desse olhar apresentaram soluções práticas diversas como a observação da difusão espacial e possibilidades de implementar barreiras geográficas a essa morbidade (geografia, epidemiologia), a elaboração de máscaras com materiais que servissem como uma melhor barreira ou mesmo eliminasse o vírus que causa a Covid-19 (engenharia de materiais), a observação dos cuidados terapêuticos mais eficientes (enfermeiros, médicos), a elaboração de vacinas (farmacêutico, biomédico, médico imunologista, engenheiro químico) entre várias outras ciências.

\section{ESCOLHA DAS PESQUISAS A SEREM ANALISADAS}

Os resultados das pesquisas consideradas foram distintos, sendo reunidas em um quadro para melhor esclarecer o leitor (quadro 1). Dentre esses trabalhos, os que estão menos relacionados à Geografia da Saúde seriam as pesquisas 1 "Desafios e potencialidades do trabalho de campo nos cursos de Geografia nas Instituições de Ensino Superior da Paraíba"; 3. "Desafios e potencialidades do trabalho de campo nos cursos de Geografia em Instituições de Ensino Superior no Brasil" e 7 "Trajetórias epistemológicas da Geografia: uma análise do conceito de território nos estudos agrários", não sendo considerados neste trabalho.

Desta forma, os trabalhos que estariam mais próximos a Geografia da Saúde seriam: a) 2 "Conhecimento geográfico aplicado aos roteiros de campo em Geografia da Saúde no município de Campina Grande - PB e municípios circunvizinhos"; b) 4 "Conhecimento geográfico aplicado aos roteiros de campo em Geografia da Saúde no município de Campina Grande - PB"; c) 5 "Teorias aplicáveis à Geografia da Saúde: uma revisão da literatura" e; d) 6 "Situação do Grupo de Pesquisa em Geografia da Saúde para promoção da Saúde em relação aos grupos de pesquisa em Geografia e Saúde no Brasil". Estes trabalhos serão denominados por números a partir deste momento.

Quadro 01 - Pesquisas realizadas entre 2010 e 2020 no âmbito do pró-saúde Geo na linha "metodologia da pesquisa e ensino"

\begin{tabular}{|c|c|c|c|}
\hline TÍTULO/ PROGRAMA/ OBJETIVO & $\begin{array}{c}\text { PERÍODO/ } \\
\text { PROCEDIMENTOS } \\
\text { METODOLÓGICOS }\end{array}$ & PRINCIPAIS RESULTADOS & REFERÊNCIAS \\
\hline $\begin{array}{l}\text { 1. Desafios e potencialidades } \\
\text { do trabalho de campo nos } \\
\text { cursos de Geografia das } \\
\text { Instituições de Ensino } \\
\text { Superior da Paraíba/ PIVIC/ } \\
\text { Entender os desafios e } \\
\text { potencialidades do trabalho } \\
\text { de campo em cursos de } \\
\text { graduação em Geografia no } \\
\text { Estado da Paraíba }\end{array}$ & $\begin{array}{l}2012-2013 / \text { a) } \\
\text { levantamento de } \\
\text { referências; b) } \\
\text { levantamento } \\
\text { documental; c) } \\
\text { realização de } \\
\text { entrevistas } \\
\text { individuais; d) } \\
\text { espacialização dos } \\
\text { resultados. }\end{array}$ & $\begin{array}{l}\text { Há relato de problemas externos para } \\
\text { realização do trabalho de campo devido à } \\
\text { burocracia e ausência de condições } \\
\text { logísticas; relacionado às disciplinas foi } \\
\text { demonstrada falta de planejamento no que } \\
\text { diz respeito a ausência do uso do método } \\
\text { científico para sustentar a utilização deste } \\
\text { método de procedimento. Enfatiza-se que } \\
\text { o trabalho de campo é uma metodologia } \\
\text { que deve se perpetuar na Geografia. As } \\
\text { análises em cada disciplina só podem ser } \\
\text { entendidas, quando ultrapassamos o } \\
\text { conceito e partimos para e experiência. }\end{array}$ & $\begin{array}{c}\text { Xavier e } \\
\text { Pereira } \\
\text { (2013); } \\
\text { Pereira } \\
(2017)\end{array}$ \\
\hline $\begin{array}{l}\text { 2. Conhecimento geográfico } \\
\text { aplicado aos roteiros de } \\
\text { campo em Geografia da } \\
\text { Saúde no município de } \\
\text { Campina Grande - PB e } \\
\text { municípios circunvizinhos/ } \\
\text { PIBIC/ Utilizar o conhecimento } \\
\text { geográfico na definição de } \\
\text { roteiros que possibilitem a } \\
\text { visualização de elementos de } \\
\text { promoção, prevenção e risco } \\
\text { à saúde no município de } \\
\text { Campina Grande e municípios } \\
\text { circunvizinhos. }\end{array}$ & $\begin{array}{l}\text { 2013-2014/ a) } \\
\text { levantamento de } \\
\text { referências; b) } \\
\text { levantamento } \\
\text { documental; c) } \\
\text { aplicação de } \\
\text { formulários; d) } \\
\text { trabalho de campo; } \\
\text { e) elaboração dos } \\
\text { resultados }\end{array}$ & $\begin{array}{l}\text { Considera-se que o conhecimento } \\
\text { geográfico é fundamental para a } \\
\text { visualização dos roteiros de campo } \\
\text { identificando os elementos de prevenção, } \\
\text { promoção e risco à saúde e a necessidade } \\
\text { de novas pesquisas no âmbito da } \\
\text { Geografia da Saúde. }\end{array}$ & $\begin{array}{c}\text { Silva e } \\
\text { Pereira } \\
\text { (2014); } \\
\text { Silva } \\
\text { (2014); } \\
\text { Silva e } \\
\text { Pereira } \\
\text { (2015). }\end{array}$ \\
\hline
\end{tabular}

Hygeia Uberlândia - MG $\quad$ Edição especial: X GeoSaude $\quad$ Fev./2022 p. 136-154 Página 139


Pesquisas realizadas pelo Pró-Saúde Geo entre 2010 e 2020 na

área de metodologia da pesquisa e ensino: teorias, grupos de

pesquisa e trabalho de campo

Martha Priscila Bezerra Pereira

Quadro 01 - Pesquisas realizadas entre 2010 e 2020 no âmbito do pró-saúde Geo na linha "metodologia da pesquisa e ensino" (cont.)

\begin{tabular}{|c|c|c|c|}
\hline TíTULO/ PROGRAMA/ OBJETIVO & $\begin{array}{c}\text { PERÍODO/ } \\
\text { PROCEDIMENTOS } \\
\text { METODOLÓGICOS } \\
\end{array}$ & PRINCIPAIS RESULTADOS & REFERÊNCIAS \\
\hline $\begin{array}{l}\text { 3. Desafios e potencialidades } \\
\text { do trabalho de campo nos } \\
\text { cursos de Geografia em } \\
\text { instituições de Ensino Superior } \\
\text { no Brasil/ PIVIC/ Entender os } \\
\text { desafios e potencialidades do } \\
\text { trabalho de campo em cursos } \\
\text { de graduação em Geografia } \\
\text { em instituições de ensino } \\
\text { superior no Brasil }\end{array}$ & $\begin{array}{l}\text { 2014-2015/ a) } \\
\text { levantamento de } \\
\text { referências; b) } \\
\text { levantamento } \\
\text { documental; c) } \\
\text { aplicação de } \\
\text { questionário via e- } \\
\text { mail; d) } \\
\text { elaboração de } \\
\text { mapas } \\
\text { (espacialização } \\
\text { dos locais das } \\
\text { atividades de } \\
\text { campo no Ensino } \\
\text { Superior). }\end{array}$ & $\begin{array}{l}\text { Como principal resultado ficou evidente } \\
\text { que os professores expressam suas } \\
\text { ideias com relação ao trabalho de } \\
\text { campo de forma genérica como } \\
\text { mediadora entre a teoria e a prática no } \\
\text { meio estudado. }\end{array}$ & $\begin{array}{c}\text { Souza e } \\
\text { Pereira } \\
(2015)\end{array}$ \\
\hline $\begin{array}{l}\text { 4. Conhecimento geográfico } \\
\text { aplicado aos roteiros de } \\
\text { campo em Geografia da } \\
\text { Saúde no município de } \\
\text { Campina Grande - PB/ PIVIC/ } \\
\text { Utilizar o conhecimento } \\
\text { geográfico na definição de } \\
\text { roteiros que possibilitem a } \\
\text { visualização de elementos de } \\
\text { promoção, prevenção e risco à } \\
\text { saúde no município de } \\
\text { Campina Grande - PB }\end{array}$ & $\begin{array}{l}\text { 2015-2016/ a) } \\
\text { levantamento de } \\
\text { referências; b) } \\
\text { levantamento } \\
\text { documental; c) } \\
\text { aplicação de } \\
\text { formulários; d) } \\
\text { trabalho de } \\
\text { campo; e) } \\
\text { elaboração de um } \\
\text { banco de } \\
\text { informações e; f) } \\
\text { espacialização } \\
\text { dos roteiros. }\end{array}$ & $\begin{array}{l}\text { Além dos possíveis roteiros de campo, } \\
\text { foi possível compreender a 'dinâmica' } \\
\text { da cidade e, em que afeta ou ajuda a } \\
\text { população às ações dos gestores. } \\
\text { Também se pode compreender a } \\
\text { importância desse trabalho para } \\
\text { tomada de decisões, em apoio a } \\
\text { sociedade e para o uso do } \\
\text { conhecimento geográfico e científico. }\end{array}$ & $\begin{array}{l}\text { Lima e } \\
\text { Pereira } \\
\text { (2016); Lima } \\
\text { e Pereira } \\
\text { (2018) }\end{array}$ \\
\hline $\begin{array}{l}\text { 5. Teorias aplicáveis à } \\
\text { Geografia da Saúde: uma } \\
\text { revisão da literatura/ PIVIC/ } \\
\text { Analisar as aplicações de } \\
\text { teorias para a Geografia da } \\
\text { Saúde }\end{array}$ & $\begin{array}{l}2016-2017 / \text { a) } \\
\text { levantamento de } \\
\text { referências; b) } \\
\text { levantamento na } \\
\text { internet; c) } \\
\text { levantamento } \\
\text { sistemático de } \\
\text { teorias; d) } \\
\text { elaboração de um } \\
\text { inventário. }\end{array}$ & $\begin{array}{c}\text { Como resultados, a partir das leituras e } \\
\text { levantamentos de algumas teorias foi } \\
\text { possível conhecer mais sobre as } \\
\text { temáticas da Geografia da Saúde. O } \\
\text { inventário foi eficaz para a avaliação } \\
\text { das teorias. Neste primeiro momento, } \\
\text { as teorias analisadas foram } \\
\text { relacionadas diretamente à Geografia } \\
\text { da Saúde, contudo, serviu como piloto } \\
\text { para estudos em outros âmbitos da } \\
\text { Geografia. }\end{array}$ & $\begin{array}{c}\text { Santos e } \\
\text { Pereira } \\
(2017)\end{array}$ \\
\hline $\begin{array}{l}\text { 6. Situação do Grupo de } \\
\text { Pesquisa em Geografia da } \\
\text { Saúde para Promoção da } \\
\text { Saúde em relação aos grupos } \\
\text { de pesquisa em Geografia e } \\
\text { Saúde no Brasil/ PIVIC/ } \\
\text { Analisar a posição do Grupo } \\
\text { de Pesquisa em Geografia } \\
\text { para Promoção da Saúde em } \\
\text { relação a outros grupos da } \\
\text { Geografia da Saúde e áreas } \\
\text { afins no território brasileiro }\end{array}$ & $\begin{array}{l}\text { 2019-2020/ a) } \\
\text { levantamento de } \\
\text { referências; b) } \\
\text { levantamento na } \\
\text { internet; c) } \\
\text { espacialização } \\
\text { dos grupos de } \\
\text { pesquisa no Brasil } \\
\text { e das redes do } \\
\text { Pró-saúde Geo; d) } \\
\text { Levantamento } \\
\text { iconográfico e } \\
\text { cartográfico; e) } \\
\text { levantamento } \\
\text { documental. }\end{array}$ & $\begin{array}{l}\text { A criação dos grupos de pesquisa de } \\
\text { Geografia da Saúde no Brasil } \\
\text { acompanha a evolução desta área da } \\
\text { Geografia, e ainda está em constante } \\
\text { expansão de suas atividades científicas } \\
\text { e acadêmicas por todo o país. Também } \\
\text { é notório que existe uma rede nacional } \\
\text { no qual a maioria dos grupos de } \\
\text { pesquisa estão conectados neste } \\
\text { círculo de troca de experiências em } \\
\text { seus trabalhos realizados, e de ideias, } \\
\text { temas e novas metodologias que estão } \\
\text { sendo aplicadas nesses trabalhos. O } \\
\text { Pró-Saúde Geo tanto se conecta tanto } \\
\text { com grupos centrais quanto periféricos. }\end{array}$ & $\begin{array}{l}\text { Pereira e } \\
\text { Pereira } \\
(2020)\end{array}$ \\
\hline
\end{tabular}


Quadro 01 - Pesquisas realizadas entre 2010 e 2020 no âmbito do pró-saúde geo na linha "metodologia da pesquisa e ensino" (cont.)

\begin{tabular}{|c|c|c|c|}
\hline TÍTULO/ PROGRAMA/ OBJETIVO & $\begin{array}{c}\text { PERÍODO/ } \\
\text { PROCEDIMENTOS } \\
\text { METODOLÓGICOS }\end{array}$ & PRINCIPAIS RESULTADOS & REFERÊNCIAS \\
\hline $\begin{array}{l}\text { 7. Trajetórias epistemológicas } \\
\text { da geografia: uma análise do } \\
\text { conceito de território nos } \\
\text { estudos agrários/ PIBIC/ } \\
\text { Analisar a aplicação do } \\
\text { conceito de território nos } \\
\text { estudos da geografia agrária } \\
\text { brasileira }\end{array}$ & $\begin{array}{l}2019-2020 / \text { a) } \\
\text { revisão } \\
\text { bibliográfica; b) } \\
\text { revisão da } \\
\text { literatura; c) } \\
\text { análise } \\
\text { documental }\end{array}$ & $\begin{array}{l}\text { O conceito de território é central como } \\
\text { categoria analítica tanto da Geografia } \\
\text { quanto da Geografia Agrária. Foram } \\
\text { variadas as matrizes teóricas que } \\
\text { influenciaram os artigos analisados nos } \\
\text { Simpósios Nacionais de Geografia } \\
\text { Agrária, sendo a perspectiva crítica a } \\
\text { mais presente. Os resultados podem } \\
\text { contribuir tanto para a epistemologia do } \\
\text { conceito quanto para o conhecimento } \\
\text { da produção científica que vem sendo } \\
\text { desenvolvida e discutida. }\end{array}$ & $\begin{array}{l}\text { Silva e Lima } \\
\quad(2020)\end{array}$ \\
\hline
\end{tabular}

Acervo do Pró-Saúde Geo (2021). Organizado pela autora.

\section{PESQUISA SOBRE TEORIAS:}

A pesquisa sobre teorias (5) buscou inicialmente resgatar o conceito de teorias e suas características buscando possibilidades de identificação do que realmente poderia ser considerado uma teoria em meio a tantas ideias propostas no fazer científico.

Em síntese, a teoria seria uma maneira de viabilizar o entendimento de determinados fatos ou uma abordagem do mundo sensível a partir da organização de ideias, sendo expressos através de conceitos, classificações, princípios, generalizações, dentre outras formas. A teoria possui várias características (quadro 2).

Quadro 02 - Características das teorias

\begin{tabular}{|l|l|}
\hline \multicolumn{1}{|c|}{ CARACTERÍSTICA } & \multicolumn{1}{|c|}{ REFERÉNCIAS } \\
\hline a) é elaborada em um contexto histórico definido & Chauí (2001) \\
\hline b) está em busca de uma explicação causal de certo acontecimento & $\begin{array}{l}\text { Popper (2013) e Demo } \\
(2014)\end{array}$ \\
\hline c) deve estar preparada para não se enganar com qualquer aparência & Carvalho (2013) \\
\hline d) precisa ser posta à prova, sendo necessárias revisões periódicas das teorias & $\begin{array}{l}\text { Demo (2014), Popper } \\
\text { (2013) e Kuhn (2013) }\end{array}$ \\
\hline e) possui uma distinção formal entre fato e valor, meio e fim, abstrato e concreto & Demo (2014) \\
\hline f) está sempre em busca de explicações mais universais & $\begin{array}{l}\text { Carvalho (2013) e Popper } \\
\text { (2013) }\end{array}$ \\
\hline $\begin{array}{l}\text { g) as teorias particulares são verificáveis, porém, quanto mais universal se torna } \\
\text { uma teoria, menor a possibilidade de verificação }\end{array}$ & Popper (2013) \\
\hline h) uma teoria pode englobar outra & Carvalho (2013) \\
\hline $\begin{array}{l}\text { i) o falseamento de uma conclusão acarreta o falseamento de tudo o que deriva } \\
\text { desse sistema falseado }\end{array}$ & Popper (2013) \\
\hline $\begin{array}{l}\text { j) pode-se falsear uma nova teoria particular sem abalar as hipóteses mais gerais, } \\
\text { mais universais }\end{array}$ & Popper (2013) \\
\hline k) o declínio de regras existentes é a sinalização para a busca de novas regras & Kuhn (2013) \\
\hline $\begin{array}{l}\text { l) os axiomas de uma teoria são formulados de tal forma que todos os outros } \\
\text { enunciados pertencentes ao sistema teórico possam ser derivados desses } \\
\text { axiomas }\end{array}$ & Popper (2013) \\
\hline $\begin{array}{l}\text { m) um sistema teórico deixa de ser hipotético e passa a ser axiomático se estiver } \\
\text { livre de contradição, for independente, a partir dele se deduz os outros } \\
\text { enunciados }\end{array}$ & Popper (2013) \\
\hline $\begin{array}{l}\text { n) possui um sistema de conceitos } \\
\text { o) todo e qualquer evento pode ser causalmente explicado/ resume o } \\
\text { conhecimento sobre o fenômeno }\end{array}$ & $\begin{array}{l}\text { Popper (2013), Marconi e } \\
\text { Lakatos (2010) }\end{array}$ \\
\hline p) para cada evento pode-se elaborar mais de uma construção teórica & Kuhn (2013) \\
\hline q) prevê fatos (baseado no que ocorre em outros locais em tempos diversos) & Marconi e Lakatos (2010) \\
\hline
\end{tabular}

Fonte: Pesquisa bibliográfica realizada pela autora (2016)

Hygeia Uberlândia - MG $\quad$ Edição especial: X GeoSaude $\quad$ Fev./2022 p. 136-154 Página 141


Essas características seriam norteadoras da análise das teorias que foram escolhidas no projeto, foram elas: Teoria dos Germes, Teoria dos focos naturais, teoria dos complexos patogênicos, teoria da história natural das doenças, teoria da saúde-doença como processo social, teoria da determinação da saúde. Em relação aos métodos de procedimento, esta foi uma pesquisa bibliográfica, de gabinete e que utilizou o método tipológico (quadro 3).

\begin{tabular}{|c|c|c|c|c|c|c|}
\hline \multicolumn{7}{|c|}{ Quadro 03 - Análise das teorias } \\
\hline CARACTERÍSTICA & $\begin{array}{l}\text { TEORIA } \\
\text { DOS } \\
\text { GERMES }\end{array}$ & $\begin{array}{l}\text { TEORIA } \\
\text { DOS } \\
\text { FOCOS } \\
\text { NATURAIS }\end{array}$ & $\begin{array}{l}\text { TEORIA DOS } \\
\text { COMPLEXOS } \\
\text { PATOGEENICO } \\
\text { S }\end{array}$ & $\begin{array}{l}\text { TEORIA DA } \\
\text { HISTÓRIA } \\
\text { NATURAL } \\
\text { DAS } \\
\text { DOENÇAS }\end{array}$ & $\begin{array}{c}\text { TEORIA DA } \\
\text { SAÚDE E } \\
\text { DOENÇA } \\
\text { COMO } \\
\text { PROCESSO } \\
\text { SOCIAL }\end{array}$ & $\begin{array}{l}\text { TEORIA DA } \\
\text { DETERMINAÇÃO } \\
\text { SOCIAL DA } \\
\text { SAÚDE }\end{array}$ \\
\hline $\begin{array}{l}\text { é elaborada em um contexto } \\
\text { histórico definido }\end{array}$ & & & & & & \\
\hline $\begin{array}{l}\text { busca uma explicação causal de } \\
\text { certo acontecimento }\end{array}$ & & & & & & \\
\hline $\begin{array}{l}\text { preparada para não se enganar } \\
\text { com qualquer aparência }\end{array}$ & & & & & & \\
\hline $\begin{array}{l}\text { precisa ser posta à prova, sendo } \\
\text { necessárias revisões periódicas } \\
\text { das teorias/ deve preencher } \\
\text { lacunas no conhecimento }\end{array}$ & & & & & & \\
\hline $\begin{array}{l}\text { possui uma distinção formal entre } \\
\text { fato e valor, meio e fim, abstrato e } \\
\text { concreto }\end{array}$ & & & & & & \\
\hline $\begin{array}{lll}\text { está sempre em busca de } \\
\text { explicações mais universais }\end{array}$ & & & & & & \\
\hline teoria particular & & & & & & \\
\hline teoria generalizada & & & & & & \\
\hline Teoria capaz de incluir outras & & & & & & \\
\hline possui um sistema de conceitos & & & & & & \\
\hline $\begin{array}{l}\text { todo e qualquer evento pode ser } \\
\text { causalmente explicado/ resume o } \\
\text { conhecimento sobre o fenômeno }\end{array}$ & & & & & & \\
\hline $\begin{array}{l}\text { para cada evento pode-se elaborar } \\
\text { mais de uma construção teórica }\end{array}$ & & & & & & \\
\hline prevê fatos & & & & & & \\
\hline
\end{tabular}

Organização: SANTOS, G.M.S. \& PEREIRA, M.P.B (2017)/ Observação: Os itens foram adaptados para analisar as teorias, sendo omitidas algumas características que não se aplicavam a análise proposta.

Legenda:

Foi observado

Não foi observado

A teoria dos germes apresenta a ideia de que muitas das morbidades são causadas por infecções por microrganismos. Essa teoria foi demonstrada inicialmente por Louis Pasteur na segunda metade do século XIX, apesar de ser a maturação de uma ideia que já existia anteriormente (desde o século XVI. Essa teoria teve início com um problema particular (resolver a questão do vinho e da cerveja azedarem) e se ampliou paulatinamente (GOUVEIA-MATOS, 1997; TORTORA, FUNKE e CASE, 2017).

A teoria dos focos naturais foi desenvolvida por $\mathrm{Y}$. N. Pavlovsky a partir do avanço da fronteira agrícola soviética marcado pelo cunho ecologista. Destacou-se por estabelecer o conceito de que o espaço era o cenário no qual circulava o agente infeccioso (SILVA, 1997). A epidemiologia paisagística, que é a delimitação geográfica de áreas propícias ao desenvolvimento de zoonoses, foi uma das principais contribuições da teoria dos focos naturais, sendo de suma importância para o planejamento de empreendimentos no momento histórico em que foi idealizada a teoria. Essa teoria foi aplicada a pesquisas epidemiológicas da então União das Repúblicas Socialistas Soviéticas durante a década de 1940 (PAVLOVSKY, 1960; SANTOS, STEINKE, OLIVEIRA, GARCIA-ZAPATA, 2016).

A Teoria dos complexos patogênicos foi desenvolvida na década de 1940 por Maximilien Sorre. Busca estudar um enfoque geográfico da relação entre o meio ambiente e sua influência na saúde (SORRE, 1955). Essa teoria foi desenvolvida num período de expansão da sociedade urbano-industrial

Hygeia Uberlândia - MG $\quad$ Edição especial: X GeoSaude $\quad$ Fev./2022 p. 136-154 Página 142


que trouxe como consequências transformações ecológicas sem precedentes, principalmente na questão dos fluxos de energia e dinâmica dos ciclos naturais, com sérias consequências ambientais (GUIMARÃES, 2015). Devido essa realidade estar ocorrendo em vários locais do planeta essa teoria se popularizou.

A teoria da História Natural das Doenças foi desenvolvida por Hugh Leavell e E. Gurney Clark tendo como obra marco o livro "Medicina Preventiva", publicada originalmente no ano de 1965. Refere-se ao conjunto de processos interativos que ocorrem entre o agente, o suscetível e o ambiente. No ambiente são criados estímulos patológicos a partir dos agentes que podem atingir o ser humano, sendo as possíveis consequências a cronicidade (temporária ou permanente), a recuperação/ cura, invalidez ou morte (LEAVELL \& CLARCK, 1976; ROUQUAYROL \& GURGEL, 2013).

A Teoria da Saúde e doença como processo social idealizada por Asa Cristina Laurell (1982) afirma que o processo saúde-doença deve ser buscado na forma como a sociedade se organiza para a construção da vida social. As principais ideias defendidas são: a) a doença efetivamente tem caráter histórico e social; b) Para compreender o processo saúde-doença como um processo social é necessário ter claro qual será o grupo estudado. Deve ser selecionado com base em suas características sociais, da forma como se inserem no processo de trabalho da sociedade; c) o processo saúde-doença é determinado pela maneira como o ser humano se apropria da natureza em um determinado momento através do trabalho (LAURELL, 1982).

A Teoria da Determinação Social da Saúde defende que em cada lugar as condições de saúde dependem dos contextos de vida a que está submetido determinado grupo social, este contexto definiria socialmente a qualidade da saúde do indivíduo (DAHLGREN \& WHITEHEAD, 2006). Em seu modelo, demonstrado por Lima e Santos (2018) (esquema explicativo 1), é demonstrado que a partir da escala do corpo (constituição biológica) o indivíduo sofre influência em várias escalas, ou seja, após a escala do corpo, sofre influência da família (estilo de vida), da comunidade (redes sociais e comunitárias), do local de moradia, do trabalho, da educação recebida, do governo a que está submetido, dentre outras variáveis e escalas (esquema explicativo 1).

Esquema explicativo 1: modelo da determinação da saúde

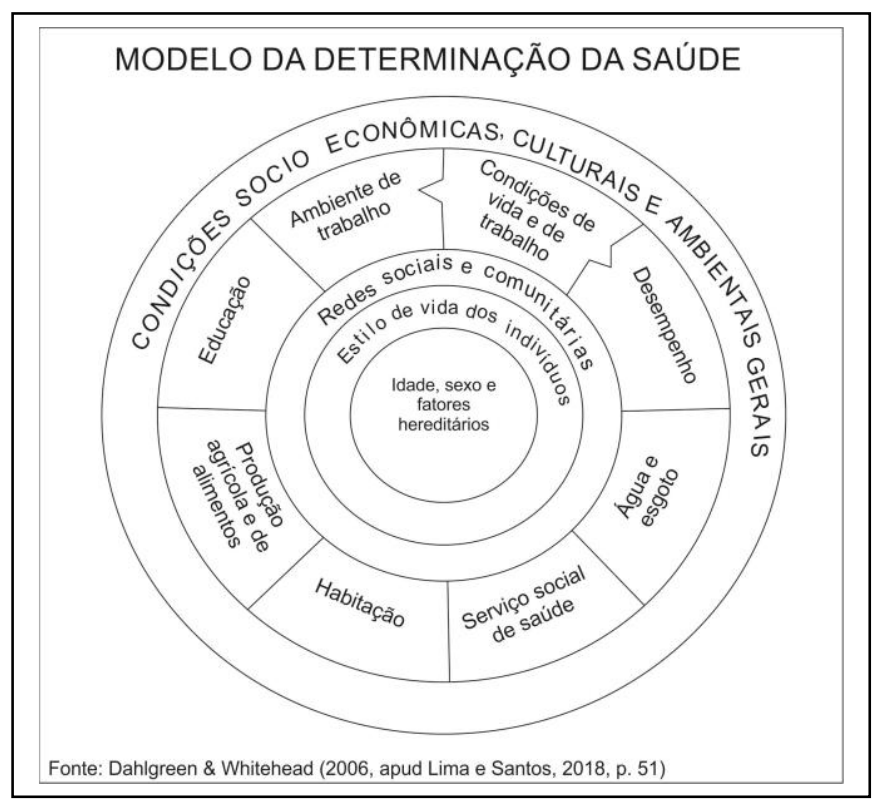

Fonte: Dahlgreen \& Whitehead (2006, apud Lima e Santos, 2018, p. 51).

A maioria dessas teorias são bem amplas, agregando um grande número de estudos que tem relação com a saúde e com a geografia, sendo de grande importância para a Geografia da Saúde, respeitandose sua relação com os métodos científicos a que estão atrelados.

Hygeia Uberlândia - MG $\quad$ Edição especial: X GeoSaude $\quad$ Fev./2022 p. 136-154 Página 143




\section{PESQUISA SOBRE GRUPOS DE PESQUISA EM GEOGRAFIA DA SAÚDE E CORRELACIONADOS}

A pesquisa sobre os grupos de pesquisa (6) teve duas teorias a serem tratadas como principais: a Teoria das Redes Sociais e a Teoria da Interdependência Espacial.

$\mathrm{Na}$ Teoria das Redes Sociais é defendido que: a) no núcleo há laços mais fortes e na periferia os laços são mais fracos; b) a organização dessas redes pode ser cooperativa, competitiva ou geradora de conflito. Quando ela é cooperativa, é capaz de gerar uma estrutura (RECUERO, 2005). A partir dessa teoria buscou-se, a partir dos grupos de pesquisa que estão também no ciberespaço, quais seriam as organizações mais cooperativas.

Ao observar a possibilidade de geração de padrões de sincronismo e de clusterização, pode-se remeter a Teoria da Interdependência espacial. Ao se considerar essa teoria há a necessidade de se considerar a distribuição relativa dos objetos, que seguem padrões e arranjos espaciais (se for uma informação espacial), assim como que quanto mais próximos geograficamente os objetos ou um evento, maior a probabilidade de eles serem semelhantes (FERREIRA, 2007). No caso da pesquisa 6 , foram trabalhadas propriedades não espaciais, que podem se transformar em layers no espaço geográfico para representar a relação entre pesquisas de maneiras variadas. Sendo possível tanto a representação da localização no nó (localização da sede do Grupo de Pesquisa) e de sua área de abrangência, assim como das redes formadas a partir de cada nó, dentre outras possíveis variações. No que diz respeito aos métodos de procedimento, esta foi uma pesquisa bibliográfica, documental e realizada em gabinete.

A base dessa pesquisa foi o Diretório dos Grupos de Pesquisa do Brasil da Plataforma Lattes, a partir disso, foi utilizado como ferramenta de pesquisa sobre os grupos de pesquisa de Geografia da Saúde atuantes no Brasil, para tal foram usadas palavras-chave que se referem a este tema, tais como: Geografia da Saúde, Cartografia da Saúde, Saúde Espaço, Território Saúde. A partir dos resultados fornecidos pela plataforma, foi elaborada uma lista (quadro 4) com as características básicas de cada um dos 32 (trinta e dois) grupos de pesquisa que pertencem ou se relacionam com a Geografia da Saúde.

Quadro 4: Grupos de pesquisa de geografia da saúde

\begin{tabular}{|c|c|c|c|}
\hline NOME DO GRUPO & LÍDER (ES) & SEDE (UNIVERSIDADE) & $\begin{array}{l}\text { ANO DE } \\
\text { CRIACÃO }\end{array}$ \\
\hline $\begin{array}{l}\text { 1. Núcleo } \\
\text { Geoprocessamento }\end{array}$ & $\begin{array}{ll}\text { Fiocruz } & \text { Fundação } \\
\text { Oswaldo Cruz }- \text { RIO DE } \\
\text { JANEIRO }\end{array}$ & $\begin{array}{l}\text { Fiocruz - Fundação Oswaldo Cruz - RIO } \\
\text { DE JANEIRO }\end{array}$ & 1994 \\
\hline $\begin{array}{lrr}2 . \quad \text { Laboratório } & \text { de } \\
\text { Geografia Médica } & \text { e } \\
\text { Vigilância em Saúde } & \end{array}$ & Samuel do Carmo Lima & $\begin{array}{l}\text { UFU - Universidade } \\
\text { Uberlândia }\end{array}$ & 1998 \\
\hline $\begin{array}{l}\text { 3. Laboratório de } \\
\text { Biogeografia e Geografia } \\
\text { da Saúde - BioGEOS }\end{array}$ & Raul Borges Guimarães & UNESP - PRESIDENTE PRUDENTE & 2004 \\
\hline $\begin{array}{l}\text { 4. Grupo de Pesquisa em } \\
\text { Geografia para Promoção } \\
\text { da Saúde - Pró-saúde Geo }\end{array}$ & $\begin{array}{lll}\text { Martha } & \text { Priscila } & \text { Bezerra } \\
\text { Pereira } & & \\
\end{array}$ & UFCG - CAMPINA GRANDE & 2010 \\
\hline $\begin{array}{l}\text { 5. LiSS - Laboratório de } \\
\text { investigação em sistemas } \\
\text { socioambientais }\end{array}$ & $\begin{array}{lll}\text { Antonio } & \text { Miguel Vieira } \\
\text { Monteiro } & & \end{array}$ & $\begin{array}{l}\text { INPE - Instituto Nacional de Pesquisas } \\
\text { Espaciais - SÃO JOSÉ DOS CAMPOS }\end{array}$ & 2010 \\
\hline 6. GeoSaúde Manaus & $\begin{array}{ll}\text { Antonio } & \text { Estanislau } \\
\text { Sanches } & \\
\end{array}$ & UEA - MANAUS & 2010 \\
\hline $\begin{array}{l}\text { 7. SIGSaúde - Geografia e } \\
\text { Análise Espacial em } \\
\text { Saúde }\end{array}$ & $\begin{array}{lll}\text { Emerson Soares dos } \\
\text { Santos }\end{array}$ & UFMT - CUIABÁ & 2012 \\
\hline $\begin{array}{l}\text { 8. NEFRONS - Núcleo de } \\
\text { Estudos sobre Fronteiras e } \\
\text { Saúde }\end{array}$ & Paulo Peiter & Fiocruz - Fundação Oswaldo Cruz & 2012 \\
\hline $\begin{array}{l}\text { 9. Geotecnologias na } \\
\text { Gestão Municipal }\end{array}$ & $\begin{array}{ll}\text { Carolina Larrosa } & \text { De } \\
\text { Oliveira Claro } & \\
\end{array}$ & $\begin{array}{l}\text { IFRS - INSTITUTO FEDERAL DO RIO } \\
\text { GRANDE DO SUL - RIO GRANDE }\end{array}$ & 2013 \\
\hline
\end{tabular}

Hygeia Uberlândia - MG $\quad$ Edição especial: X GeoSaude $\quad$ Fev./2022 p. 136-154 Página 144


Pesquisas realizadas pelo Pró-Saúde Geo entre 2010 e 2020 na

área de metodologia da pesquisa e ensino: teorias, grupos de

pesquisa e trabalho de campo

Martha Priscila Bezerra Pereira

Quadro 4: Grupos de pesquisa de geografia da saúde (cont.)

\begin{tabular}{|c|c|c|c|}
\hline NOME DO GRUPO & LÍDER (ES) & SEDE (UNIVERSIDADE) & $\begin{array}{l}\text { ANO DE } \\
\text { CRIAÇÃO }\end{array}$ \\
\hline $\begin{array}{l}\text { 10. Vigilância em Saúde } \\
\text { Ambiental }\end{array}$ & Boscolli Barbosa Pereira & UFU - UBERLÂNDIA & 2013 \\
\hline $\begin{array}{l}\text { 11. Violências, Direitos } \\
\text { Humanos e Geografia da } \\
\text { Saúde - GEOSVIDIH }\end{array}$ & Valdeir Ribeiro de Jesus & UFMT - CUIABÁ & 2014 \\
\hline $\begin{array}{l}\text { 12.ANÁLISE ESPACIAL, } \\
\text { GEOAMBIENTE } \\
\text { SAÚDE - GEO SAÚDE }\end{array}$ & $\begin{array}{l}\text { Micheline Pimentel } \\
\text { Ribeiro Cavalcante, } \\
\text { Tássia Silvana Borges }\end{array}$ & CELUP-ULBRA - PALMAS & 2014 \\
\hline $\begin{array}{lr}\text { 13. Grupo de } & \text { Pesquisa } \\
\text { Multidisciplinar } & \text { em } \\
\text { Ciências e Geotecnologias }\end{array}$ & $\begin{array}{l}\text { Eduardo Augusto } \\
\text { Werneck Ribeiro }\end{array}$ & 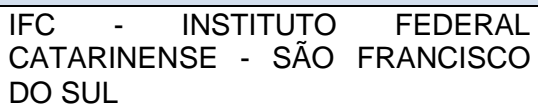 & 2014 \\
\hline $\begin{array}{l}\text { 14. LABOCLIMA } \\
\text { Laboratório de } \\
\text { Climatologia }\end{array}$ & $\begin{array}{lll}\text { Francisco } & \text { de } & \text { Assis } \\
\text { Mendonça } & & \end{array}$ & UFPR - CURITIBA & 2014 \\
\hline $\begin{array}{l}\text { 15. LAGAS - Laboratório } \\
\text { de Geografia, Ambiente e } \\
\text { Saúde }\end{array}$ & Helen Gurgel & UnB - BRASÍLIA & 2014 \\
\hline $\begin{array}{l}\text { 16. Saúde Coletiva e } \\
\text { Geografia da Saúde }\end{array}$ & Denecir de Almeida Dutra & UNIANDRADE - CURITIBA & 2015 \\
\hline $\begin{array}{l}\text { 17. Geografia da Saúde e } \\
\text { Vigilância Socioambiental }\end{array}$ & $\begin{array}{l}\text { Nelcioney José de Souza } \\
\text { Araújo }\end{array}$ & UFAM - MANAUS & 2015 \\
\hline $\begin{array}{l}\text { 18. LASA - Laboratório de } \\
\text { Aplicações de Satélites } \\
\text { Ambientais }\end{array}$ & $\begin{array}{l}\text { Renata Libonati dos } \\
\text { Santos }\end{array}$ & UFRJ - RIO DE JANEIRO & 2015 \\
\hline $\begin{array}{l}\text { 19. Grupo de Pesquisa } \\
\text { Saúde e Ambiente }\end{array}$ & $\begin{array}{l}\text { Zulimar Márita Ribeiro } \\
\text { Rodrigues }\end{array}$ & UFMA - SÃO LUÍS & 2015 \\
\hline $\begin{array}{l}\text { 20. Grupo de Pesquisa } \\
\text { GESF - Saúde, Espaço e } \\
\text { Fronteira(s) }\end{array}$ & Adeir Archanjo da Mota & UFGD - DOURADOS & 2015 \\
\hline $\begin{array}{l}\text { 21. Política, Avaliação e } \\
\text { Gestão em Saúde (PAGS) }\end{array}$ & $\begin{array}{l}\text { Rafael Gomes Ditterich, } \\
\text { Solena Ziemer Kusma }\end{array}$ & UFPR - CURITIBA & 2016 \\
\hline $\begin{array}{l}\text { 22. EU\&S - Espaço } \\
\text { Urbano e Saúde }\end{array}$ & Lígia Vizeu Barrozo & USP - SÃO PAULO & 2016 \\
\hline \begin{tabular}{lr|}
$23 . \quad$ LMI- & Sentinela l \\
Laboratório & Misto \\
Internacional &
\end{tabular} & Emmanuel Roux & $\begin{array}{l}\text { IRD - Institut de recherche pourle } \\
\text { développement - RIO DE JANEIRO }\end{array}$ & 2017 \\
\hline $\begin{array}{l}\text { 24. Núcleo de Pesquisa } \\
\text { em Geografia da Saúde - } \\
\text { NePeGS }\end{array}$ & Rivaldo Mauro de Faria & UFSM - SANTA MARIA & 2017 \\
\hline $\begin{array}{lcl}25 . & \text { Tratamento } & \text { da } \\
\text { Informação Espacial } & \end{array}$ & $\begin{array}{l}\text { Paulo Fernando Braga } \\
\text { Carvalho }\end{array}$ & PUC MINAS - BELO HORIZONTE & 2018 \\
\hline 26. Labvirus.UFU.MG & Jonny Yokosawa & UFU - UBERLÂNDIA & 2018 \\
\hline $\begin{array}{lrr}\text { 27. Grupo de } & \text { Pesquisa } \\
\text { Geografia } & \text { e } & \text { Saúde } \\
\text { GeoSaúde } & & \\
\end{array}$ & 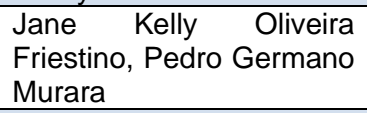 & UFFS - CHAPECÓ & 2018 \\
\hline $\begin{array}{lr}28 . \quad \text { Laboratório } & \text { de } \\
\text { Epidemiologia, } & \\
\text { Territorialidade } & \text { e } \\
\text { Sociedade - LETS } & \end{array}$ & 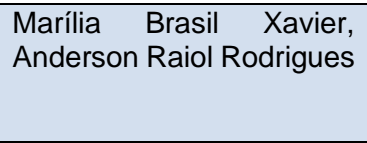 & UFPA - BELÉM & 2018 \\
\hline $\begin{array}{lr}29 . & \text { Climatologia } \\
\text { Geográfica e interfaces } \\
\text { com a saúde }\end{array}$ & Juliana Ramalho Barros & UFG - GOIÂNIA & 2018 \\
\hline $\begin{array}{l}\text { 30. DemSA: Democracia, } \\
\text { Saúde e Ambiente }\end{array}$ & $\begin{array}{l}\text { Juliana Pereira da Silva } \\
\text { Faquim }\end{array}$ & UFU - UBERLÂNDIA & 2019 \\
\hline 31. GREGS_UEM & $\begin{array}{l}\text { Maria Eugênia Moreira } \\
\text { Costa Ferreira }\end{array}$ & UEM - MARINGÁ & 2019 \\
\hline $\begin{array}{lll}\text { 32. Laboratório } & \text { de } \\
\text { Geografia da Saúde } & \end{array}$ & Rafael de Castro Catão & UFES - VITÓRIA & 2020 \\
\hline
\end{tabular}

Fonte: Magalhães e Pereira (2017); LAGAS (2020); Plataforma Lattes/ Diretório de Grupos de Pesquisa (2020); Organização: PEREIRA, EHX (2020). 
Nota-se que a criação de grupos de pesquisa nesta área da Geografia ainda é crescente e mais da metade foi fundado após o ano de 2010, tendo um pico entre os anos de 2013 e 2018 (gráfico 1).

Gráfico 1: Quantidade de grupos de pesquisa criados por ano.

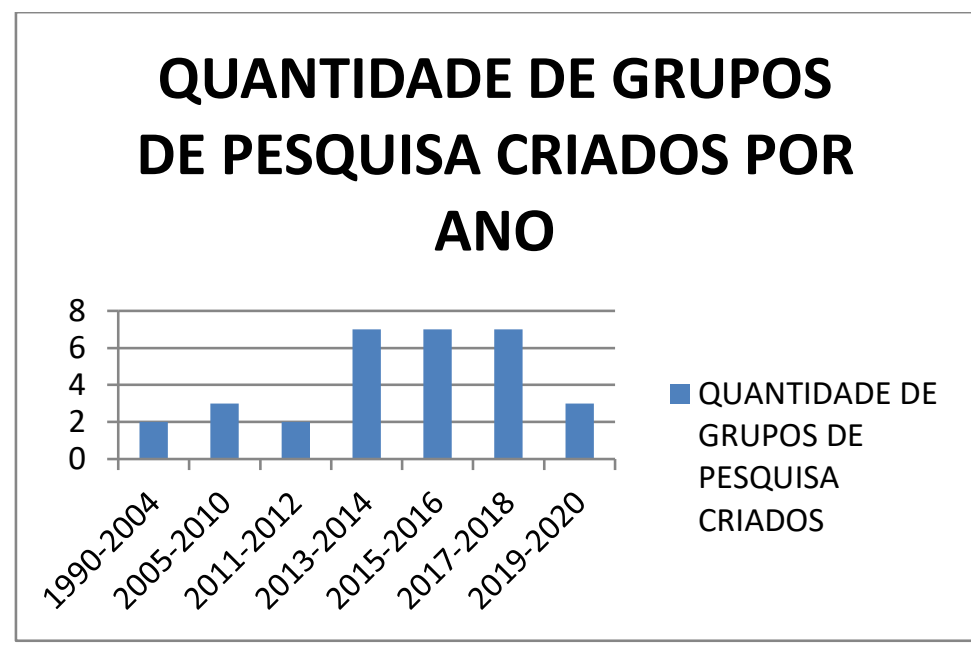

Organização: PEREIRA, EHX (2020).

Além deste notório, e recente, crescimento do número de grupos de pesquisa em Geografia da Saúde, também é explícito que existe uma grande concentração de grupos de pesquisa nos estados da região Sul e Sudeste do Brasil (Gráfico 2).

Gráfico 2: Distribuição dos grupos de pesquisa de geografia da saúde no Brasil por região.

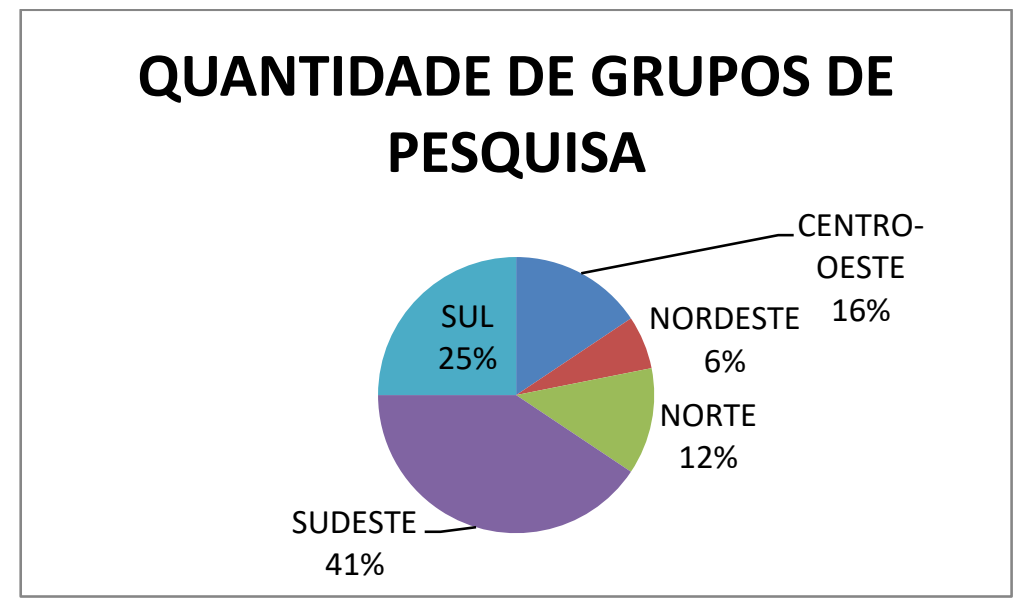

Organização: PEREIRA, EHX (2020).

No decorrer da pesquisa percebeu-se que alguns grupos de pesquisa possuíam relações entre si pelo fato de que, em algum momento, os seus líderes já se tiveram contato ao trabalhar juntos em algum projeto, pesquisa, troca de experiências exitosas entre outros fatores que permitiram que tal encontro ocorresse. A partir disso, estas conexões remeteram ao conceito de relê desenvolvido por Martins e Fontes (2004) que, em síntese, afirma que um indivíduo possui a tendência de se relacionar com outros e formar círculos de trocas de informações, e então este indivíduo pode participar de um ou mais círculos e até mesmo criar conexões formando, assim, um complexo sistema de redes sociais que está em um constante processo de renovação.

$\begin{array}{lllll}\text { Hygeia Uberlândia - MG } \quad \text { Edição especial: X GeoSaude } & \text { Fev./2022 } & \text { p. 136-154 Página } 146\end{array}$


Quando aplicamos esse conceito ao objeto de estudo desta pesquisa, percebe-se que existe uma grande conexão entre os grupos de pesquisa de Geografia da Saúde no Brasil (fluxograma 1). Esta rede é composta por alguns grupos, que podem ser denominados de centrais e dos demais grupos denominados de periféricos. Nesta rede, os grupos centrais são aqueles que possuem mais conexões com os demais grupos de pesquisa, já os grupos periféricos são os demais que constituem essa rede, entretanto, vale salientar que existem alguns grupos de pesquisa que estão fora deste círculo de troca por não possuírem nenhuma relação com qualquer outro grupo de pesquisa. Também é importante mencionar o fato de que um grupo considerado periférico não precisa ter relação direta com um determinado grupo central, pois os grupos periféricos também podem estar conectados entre si e, assim, formam novas conexões, redes e círculos de troca.

Fluxograma 1: Fluxograma das principais redes de grupos de pesquisa de Geografia da Saúde no Brasil.

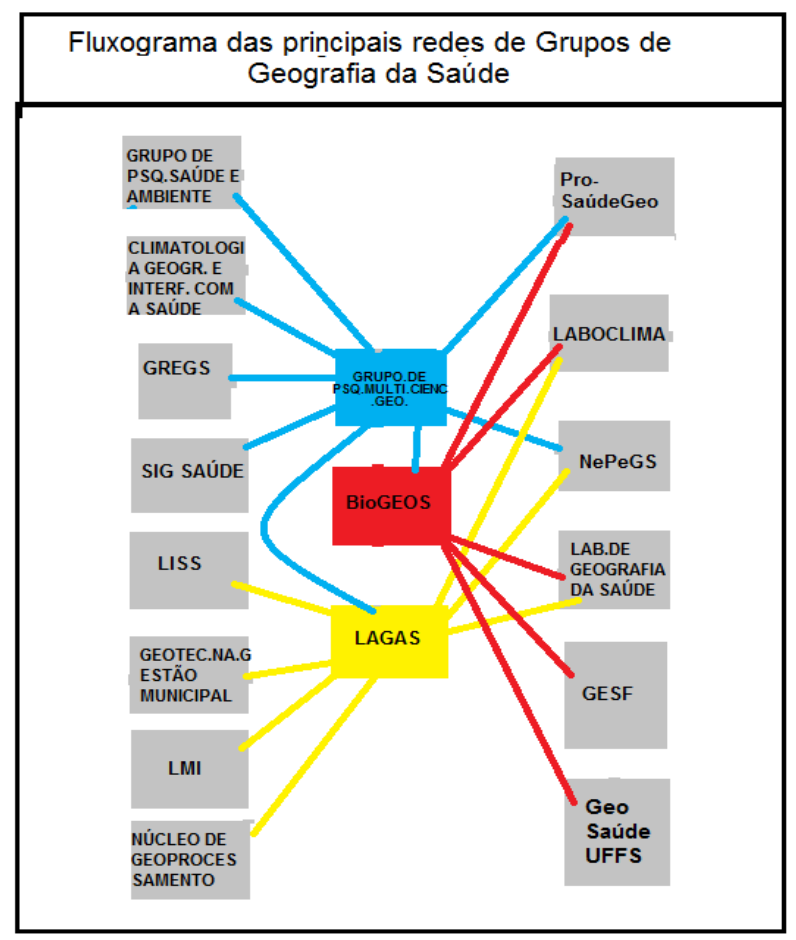

Organização: PEREIRA, EHX (2020).

Com base neste fluxograma 1, nota-se que três grupos de pesquisa constituem no topo da rede até o momento. Sendo assim, os grupos centrais são: Grupo de Pesquisa Multidisciplinar em Ciências e Geotecnologias (cor azul), o LAGAS (cor amarelo), e o BioGEOS (cor vermelho). Cada um desses grupos possuem suas próprias conexões com outros grupos de pesquisa (representados pelas linhas de suas respectivas cores), entretanto, alguns grupos periféricos (cor cinza) possuem conexão com dois grupos centrais simultaneamente, a exemplo temos o caso do Pró-Saúde Geo, que está conectado tanto com o BioGEOS quanto com o Grupo de Pesquisa Multidisciplinar em Ciências e Geotecnologias, e que por sua vez possui a sua própria rede de conexão (fluxograma 2) com outros grupos de pesquisa. 
Fluxograma 2: Fluxograma da rede do grupo Pró-Saúde Geo.

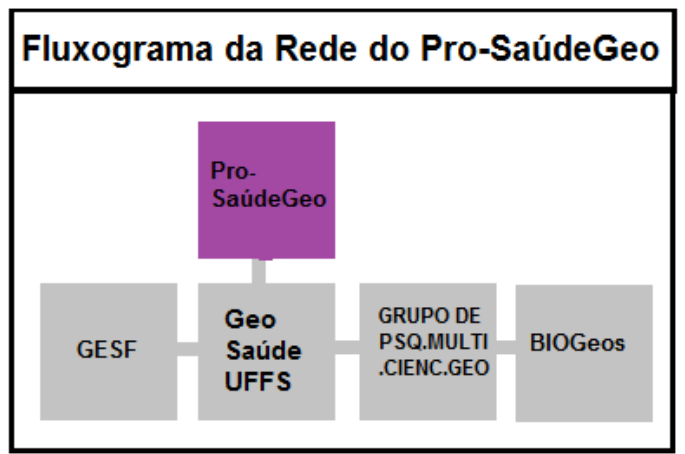

Organização: PEREIRA, EHX (2020).

Salienta-se que no fluxograma 1 estão representados apenas os grupos de pesquisa que possuem ligação direta com os grupos centrais, existem outros grupos de pesquisa que fazem parte desta rede nacional de Geografia da Saúde, que possuem as suas próprias redes e ligações com os demais grupos de pesquisa.

Os grupos de pesquisa que possuem uma rede pequena estão conectados diretamente com apenas 3 (três) outros grupos. Entretanto, isso não significa que essas "minis redes" tenham pouca circulação e troca de informações visto que, indiretamente, todos esses grupos de pesquisa menores estão conectados à rede principal de grupos de Geografia da Saúde do Brasil.

Com base nos resultados alcançados percebe-se que a criação dos grupos de pesquisa de Geografia da Saúde no Brasil acompanha a evolução da Geografia, e que ainda está em uma fase de constante expansão de suas atividades científicas e acadêmicas por todo o país. Também é notório que existe uma grande rede nacional no qual a maioria dos grupos de pesquisa dessa área estão conectados neste círculo de troca de experiências em seus trabalhos realizados, e de ideias, temas e novas metodologias que estão sendo aplicadas nesses trabalhos.

Por fim, é notável que o Pró-Saúde Geo possui uma boa conexão com os outros grupos de pesquisa do país, dentre eles estão alguns grupos centrais, como outros grupos periféricos. Esta rede do PróSaúde Geo também se deve ao fato de que ele possui o seu próprio círculo de trocas, e por ser um grupo relativamente antigo se comparado a maioria, Ihe proporcionou desenvolver uma estrutura mais consolidada e experiência com os seus trabalhos e atividades já desenvolvidas.

\section{PESQUISAS SOBRE TRABALHO DE CAMPO}

As pesquisas relacionadas ao trabalho de campo ( 2 e 4) tiveram como fundamentação teórica a discussão entre o empirismo e o racionalismo, enquanto grandes orientações da teoria do conhecimento, que, segundo Chaui (2005), evidencia as ideias de Descartes (racionalista) e Locke (empirista). A partir dessas concepções tentou-se entender como o trabalho de campo se adequa na discussão.

No cotidiano o trabalho de campo é associado ao empirismo, sendo entendido até mesmo como algo não científico (ABBAGNANO, 2012). Porém, tanto através do racionalismo quanto do empirismo há necessidade de ir a campo.

Assim sendo, a partir de um pensamento racionalista, o trabalho de campo passa a ser apenas a verificação de algo que já foi pensado, estudado, portanto, diminui a possibilidade da percepção ser ilusória. Já a partir do pensamento empirista, a experiência sensível é a fonte e fundamenta esse conhecimento, determina o valor e o sentido da atividade racional.

Ao observar essas duas características, é possível compreender que em geral, apesar de haver uma tendência por um ou por outro pensamento, há uma mescla dessas duas orientações, fazendo com que se estude e pense o local antes de visitá-lo, mas que também haja abertura para o novo, quando se está em campo, sendo a perspectiva utilizada para as pesquisas relacionadas ao trabalho de campo neste trabalho. Em relação aos métodos de procedimento, estas foram pesquisas que utilizaram o

Hygeia Uberlândia - MG $\quad$ Edição especial: X GeoSaude $\quad$ Fev./2022 p. 136-154 Página 148


método comparativo, foi de natureza quali-quantitativa e utilizou-se a metodologia da pesquisa de campo.

No que diz respeito aos procedimentos práticos nas pesquisas foi escolhido como perfil do sujeito pesquisado pessoas de profissões, situação financeira e localização de moradia diferenciada no município de Campina Grande - PB e municípios circunvizinhos.

A partir de formulários foi solicitado que o sujeito pesquisado destacasse locais (em Campina Grande ou municípios circunvizinhos) que, de acordo com a sua percepção, interferem positivamente ou negativamente na saúde física ou mental das pessoas que frequentam o local.

Foi solicitado o local, a razão do destaque e como chegar nesse local (pelo menos o bairro e o município).

Desta forma, a partir dessa abordagem, era possível surgir alguns tipos de paisagem: a) paisagem do risco (como exemplo pode-se citar: áreas de alto índice de assaltos; esgoto a céu aberto; canais urbanos sem proteção, com risco de quedas; locais com um número maior de acidentes de trânsito, feiras livres com alimentos expostos em ambientes com muitos animais e/ou sujos podendo causar algum tipo de contaminação); paisagem da prevenção (locais públicos para atividade física como a academia da cidade, academias, entre outros); paisagem da cura (ambientes religiosos, hospitais, etc) e; paisagem da promoção da saúde (como exemplos pode-se indicar os ambientes religiosos, locais de diversão, locais turísticos).

Após o destaque realizado pelos sujeitos pesquisados foi possível realizar as visitas aos locais para confirmar e realizar uma descrição inicial dos locais quanto: município, local, endereço, bairro, coordenadas geográficas, altitude, qualidade do acesso, segurança no acesso, riscos observados no local, vias de acesso a partir da universidade (no caso destes estudos - UFCG); distância do percurso (UFCG, ponto), tempo do percurso, temas observados, descrição do local (problemáticas possíveis, área da Geografia, área da Geografia da saúde, possíveis métodos científicos a serem trabalhados, conceito principal, conceitos secundários, outros possíveis conceitos, tipos de paisagem observados (risco, cura, promoção, prevenção).

Entende-se que essa descrição seria inicial pois as possibilidades de classificação são inúmeras em cada local, sendo possível identificar paisagens de risco, cura, prevenção a saúde e promoção da saúde em um mesmo ambiente, bastando destacar alguns elementos específicos na paisagem, visitar em outro momento ou mesmo mudar o observador.

A partir da breve descrição do local visitado (foram 28 locais para a pesquisa 2 e 46 locais para a pesquisa 4) foi possível traçar possíveis roteiros de trabalho de campo a partir do que se poderia encontrar no local.

\section{APLICABILIDADES}

No que diz respeito ao aproveitamento destes resultados para as disciplinas ministradas pela autora do trabalho e no grupo de pesquisa Pró-Saúde Geo percebeu-se que essas pesquisas trouxeram uma maior dinâmica no uso de teorias (pesquisa 5) tanto no processo do Trabalho de Conclusão de Curso quanto nas pesquisas de Iniciação Científica o qual os alunos passaram a discutir melhor sobre a escolha, a hierarquia, a abrangência de cada teoria e sua relação com a problemática atual.

Em relação ao trabalho 6 (sobre os grupos de pesquisa no Brasil), finalizado em 2020, já houve discussão no grupo sobre a Geografia da Saúde ser muito maior do que eles imaginavam, começaram a visualizar possibilidades de possíveis orientadores para pós-graduação nas Universidades em que estes grupos estão vinculados, além de uma maior possibilidade de conexão com alunos que participam de outros grupos de pesquisa para troca de experiências.

No que diz respeito às pesquisas sobre trabalho de campo (2 e 4), alguns dos locais incluídos já foram objeto de Iniciação científica e mesmo de TCC.

Para as disciplinas entendeu-se que essas pesquisas foram fundamentais para a melhoria da qualidade delas, ainda que não fossem diretamente a Geografia da Saúde. O aproveitamento da pesquisa sobre teorias (5) foi que os alunos das disciplinas abaixo mencionadas passaram a entender melhor as teorias e a se motivar a procurar teorias aumentando o acervo de teorias que já eram trabalhadas nas disciplinas. Há discussão sobre sua aplicabilidade por área de atuação da Geografia, em relação às problemáticas, e especificamente as teorias que foram trabalhadas na pesquisa mencionada neste

Hygeia Uberlândia - MG Edição especial: X GeoSaude $\quad$ Fev./2022 p. 136-154 Página 149


trabalho, eles buscam aplicabilidade para suas pesquisas principalmente na área da Geografia Ambiental. No que diz respeito à pesquisa sobre grupos de pesquisa (6) houve a possibilidade de mostrar a metodologia de trabalho e, devido a pandemia, eles entenderam como uma ótima possibilidade de uso aplicado às suas áreas de atuação como possibilidade de ter resultados consistentes, ainda que tenha como base informações provenientes da internet. Com relação ao trabalho de campo (2 e 4) tanto em sala de aula como em campo essas pesquisas trouxeram muitos resultados positivos, seja por ter alunos que moravam em algumas dessas áreas, por inspirar possibilidade de TCCs, por passarem a entender que o trabalho de campo deve ter uma base teóricometodológica inicial e um bom planejamento para que se aproveite melhor essa metodologia no ensino (quadro 5).

Quadro 05 - Aplicabilidade das pesquisas entre 2010 e 2020 do pró-saúde Geo na linha 'metodologia da pesquisa e ensino'

\begin{tabular}{|c|c|c|c|}
\hline \multirow{2}{*}{$\begin{array}{l}\text { ÁREA DE } \\
\text { APLICABILI DADE }\end{array}$} & \multicolumn{3}{|c|}{ PESQUISAS } \\
\hline & $\begin{array}{l}\text { PESQUISA SOBRE TEORIAS } \\
\text { (5) }\end{array}$ & $\begin{array}{l}\text { PESQUISA SOBRE GRUPOS DE } \\
\text { PESQUISA (6) }\end{array}$ & $\begin{array}{l}\text { PESQUISAS SOBRE TRABALHO DE } \\
\text { CAMPO (2 E 4) }\end{array}$ \\
\hline $\begin{array}{lr}\text { GRUPO } & \text { DE } \\
\text { PESQUISA - PRÓ- } \\
\text { SAÚDE GEO }\end{array}$ & $\begin{array}{l}\text { Auxílio aos alunos do } \\
\text { grupo de pesquisa a se } \\
\text { aprofundarem em } \\
\text { relação às teorias que se } \\
\text { aplicam à Geografia da } \\
\text { Saúde }\end{array}$ & $\begin{array}{l}\text { Identificação dos grupos de } \\
\text { pesquisa que atuam na área } \\
\text { da Geografia e Saúde para } \\
\text { buscar formas de conexão } \\
\text { com esses grupos no futuro. }\end{array}$ & $\begin{array}{l}\text { Identificação de novos } \\
\text { potenciais locais para realizar } \\
\text { pesquisas. }\end{array}$ \\
\hline $\begin{array}{l}\text { DISCIPLINA } \\
\text { GEOGRAFIA } \\
\text { SAÚDE }\end{array}$ & $\begin{array}{lr}\text { Melhora } & \text { do } \\
\text { conhecimento de teorias } \\
\text { e temáticas estudadas } \\
\text { na disciplina }\end{array}$ & $\begin{array}{l}\text { Identificação de Grupos de } \\
\text { Pesquisa que estão atuando } \\
\text { na área da Geografia e da } \\
\text { Saúde no Brasil }\end{array}$ & $\begin{array}{l}\text { Identificação de locais para } \\
\text { realização de visitas em } \\
\text { trabalho de campo }\end{array}$ \\
\hline $\begin{array}{l}\text { DISCIPLINA - } \\
\text { TEORIA E MÉTODO } \\
\text { EM GEOGRAFIA }\end{array}$ & $\begin{array}{l}\text { Aprimoramento sobre as } \\
\text { características da teoria } \\
\text { e como diferenciar as } \\
\text { teorias mais bem } \\
\text { elaboradas de teorias } \\
\text { incompletas ou sem } \\
\text { fundamento adequado. }\end{array}$ & $\begin{array}{l}\text { As teorias utilizadas para a } \\
\text { pesquisa são apresentadas } \\
\text { também aos alunos da } \\
\text { disciplina, buscando novas } \\
\text { aplicabilidades }\end{array}$ & $\begin{array}{l}\text { Utilização da discussão } \\
\text { teórica sobre trabalho de } \\
\text { campo na disciplina }\end{array}$ \\
\hline $\begin{array}{l}\text { DISCIPLINA } \\
\text { PROJETO } \\
\text { PESQUISA }\end{array}$ & $\begin{array}{lr}\text { Aproveitamento } & \text { de } \\
\text { algumas } & \text { teorias } \\
\text { trabalhadas na pesquisa } \\
\text { pararáricos. } \\
\text { especín }\end{array}$ & $\begin{array}{l}\text { A metodologia utilizada na } \\
\text { pesquisa compõe um dos } \\
\text { exemplos de pesquisa. }\end{array}$ & $\begin{array}{l}\text { Utilização da discussão } \\
\text { metodológica do trabalho de } \\
\text { campo na disciplina }\end{array}$ \\
\hline
\end{tabular}

Fonte: Experiência da autora do trabalho no grupo e nas disciplinas citadas (2010-2021); Organização: a autora.

Para exemplificar um aproveitamento dessas pesquisas para a disciplina Geografia da Saúde, especificamente as pesquisas sobre trabalho de campo $(2$ e 4$)$, dentre os roteiros possíveis traçados será apresentado o exemplo de um trabalho de campo realizado em 05/11/2018 no âmbito da disciplina Geografia da Saúde (mapa 1).

Este roteiro de trabalho de campo foi escolhido pelos alunos da disciplina para privilegiar os tipos de paisagem (risco, prevenção, cura, promoção), observar problemáticas diferenciadas (animais abandonados e maltratados; população em situação de vulnerabilidade; locais de contemplação que promovem a saúde, possível contaminação de alimentos, cultivo de plantas para melhorar a segurança alimentar e para cura de doenças) e ações exitosas que previnem doenças e/ou promovem a saúde (academia da cidade, local para caminhada, horta comunitária e horta medicinal).

Os locais escolhidos para o trabalho de campo foram: Centro de Zoonoses/Vigilância Ambiental, Parque Bodocongó, Vila dos Teimosos, UBS Aluísio Salviano Farias, Parque da Criança e Feira Central de Campina Grande, todos no município de Campina Grande - PB - Brasil. 
Mapa 01 - Campina Grande - PB - Roteiro de trabalho de campo para a disciplina geografia da saúde

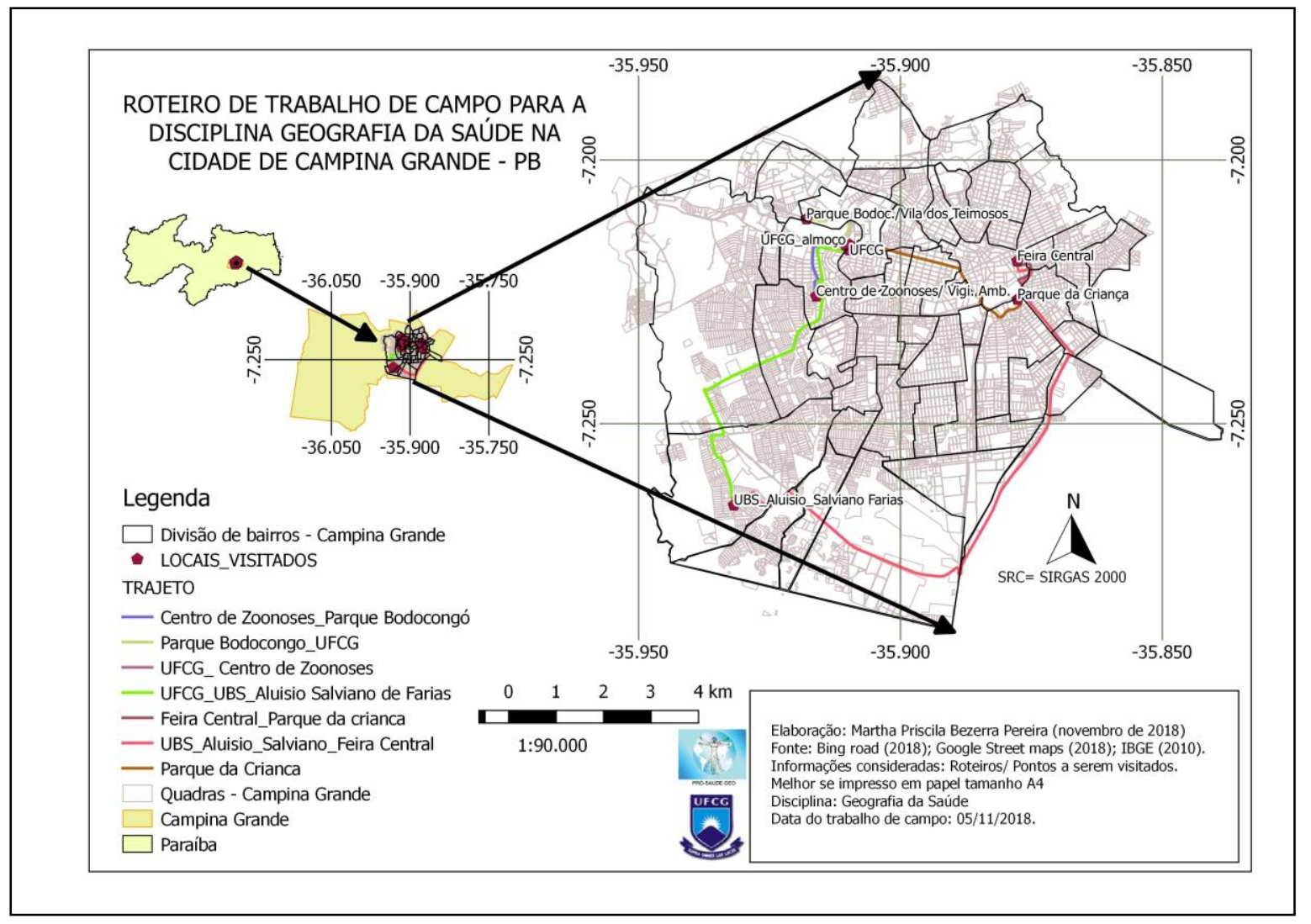

Fontes: Bing road (2018); Google Street maps (2018); IBGE (2010). Elaboração: a autora (2018).

\section{CONSIDERAÇÕES FINAIS}

Este artigo trouxe uma síntese relacionada à linha de pesquisa "Metodologia da Pesquisa e Ensino" do grupo de pesquisa Pró-Saúde Geo entre 2010 e 2020 com ênfase nas pesquisas relacionadas à Geografia da Saúde.

Os procedimentos metodológicos adotados atenderam as necessidades de elaboração desta síntese.

A fundamentação teórica norteou a concepção deste trabalho na medida em que a maneira de observar uma problemática pode se configurar como uma pista de uma cosmovisão, ainda que não seja determinante, pois ela passa por várias influências. Considerando que essas influências iniciam já na publicação de um edital de seleção de projetos.

A escolha das pesquisas relacionadas apenas à Geografia da Saúde ocorreu devido, inicialmente, à participação no X Simpósio Nacional de Geografia da Saúde (2021) e posteriormente pelo escopo desta revista.

A pesquisa sobre teorias tanto contribuiu para um maior embasamento sobre as características das teorias quanto para entender melhor algumas teorias de interesse para a Geografia da Saúde. No entanto, muito ainda pode ser realizado a partir do levantamento de artigos, teses de doutorado e livros que potencialmente servirão para embasar novas teorias, complementar ou retrabalhar teorias que são utilizadas na atualidade.

O trabalho realizado sobre os grupos de pesquisa demonstrou que alguns grupos fizeram melhores conexões em relação a outros, mas há muito o que ser feito em relação ao fortalecimento deste vínculo em geral para fortalecer a própria Geografia da Saúde no Brasil. Além disso, é um trabalho que deve ser constantemente atualizado devido a formação de novos grupos e novos profissionais que passam a lidar com a Geografia da Saúde.

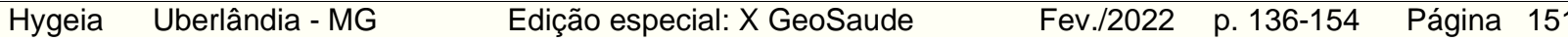


A pesquisa sobre trabalho de campo teve como maiores contribuições a descoberta de locais no município e arredores que se destacam por interferir de alguma maneira na saúde e ter elencado possíveis elementos que podem embasar a classificação de uma paisagem relacionada à saúde. Como aprofundamento pode-se comparar o que foi indicado pelo sujeito pesquisado, o que foi observado pelo aluno pesquisador com o que o aluno na disciplina elege e visualiza em campo. É igualmente interessante testar outros conceitos arraigados à Geografia para aprimorar as metodologias que estão vinculadas a esses conceitos. Há também a possibilidade de se utilizar o conhecimento adquirido nessas pesquisas para projetos de extensão no futuro.

Enfim, percebe-se que essas pesquisas, inicialmente básicas, possuem aplicabilidades tanto para o ensino quanto para o próprio grupo de pesquisa, apesar de potencialmente servir também para projetos de extensão, especialmente as pesquisas sobre trabalho de campo (2 e 4) em que se observam locais passíveis de se realizar projetos dessa natureza.

As pesquisas realizadas nessa linha de atuação do Pró-saúde Geo entre 2010 e 2020 ainda não foram abrangentes o suficiente para trabalhar uma grande variedade de metodologias de procedimento e/ou delineamentos, pois ficaram em torno do método tipológico, método comparativo, pesquisa de gabinete ou de campo, pesquisa documental ou bibliográfica, e pesquisas quali-quantitativas, algo que deve ser mais bem trabalhado em pesquisas futuras.

\section{AGRADECIMENTOS}

Agradeço ao CNPq pelas bolsas concedidas (PIBIC) e também por viabilizar o programa voluntário (PIVIC), aos alunos que participaram desses projetos e aos integrantes do grupo PRÓ-SAÚDE GEO.

\section{REFERÊNCIAS}

ABBAGNANO, N. Dicionário de Filosofia. São Paulo - SP: Martins Fontes, 2012, 1210p.

CARVALHO, M. Teoria e experiência. São Paulo -SP: Martins Fontes, 2013, 76p.

CASTORIADIS, C. A instituição imaginária da sociedade. 6.ed. Rio de Janeiro - RJ: Paz e Terra, 2007, 418p.

CASTORIADIS, C.EI mundo fragmentado. Montevideo: Editorial Nordan-Comunidad, 1990, 170p.

CASTRO, I.E. O problema da escala. In: Geografia: conceitos e temas. Rio de Janeiro - RJ: Bertrand Brasil, 1995, 353p. P. 117-140

CERVO, A.L.; BERVIAN, P.A.; SILVA, R. Metodologia Científica. 6.ed. São Paulo - SP: Pearson Prentice Hall, 2007, 162p.

CHAUÍ, M. Convite a filosofia. São Paulo - SP: Ática, 2005, 424p.

CHAUÍ, M. O que é ideologia. 2.ed. São Paulo - SP: Editora Brasiliense, 2001, 143p.

CHIZZOTTI, A. Pesquisa qualitativa em ciências humanas e sociais. 4ed. Petrópolis - RJ: Vozes, 2011, 142p.

DAHLGREN, G; WHITEHEAD, M. European strategies for tackling social inequities in health: levelling up part 2. Copenhagen - Dinamarca. 2006, 149p. Disponível em: https://www.euro.who.int/ data/assets/pdf file/0018/103824/E89384.pdf. Acesso em 06 jan. 2022.

DEMO, P. Metodologia científica em ciências sociais. 5.ed. São Paulo - SP: Atlas, 2014, 193p.

FERREIRA, A.M.A. Prefácio. In: HARDY-VALLÉE, Benoit. Que é um conceito? São Paulo - SP: Parábola, 2013, 127p.

FERREIRA, M.C. Considerações teórico-metodológicas sobre as origens e a inserção do sistema de informação geográfica na geografia. In: VITTE, Antônio Carlos (org). Contribuições à história e à epistemologia da Geografia. Rio de Janeiro - RJ: Bertrand Brasil, 2007, 294p. P. 101-125.

GIL, A.C. Como elaborar projetos de pesquisa. 5.ed. São Paulo - SP: Atlas, 2010, 184p.

GOUVEIA-MATOS, J.A.M. Pasteur. Química Nova na escola. N. 6, nov, 1997. Disponível em http://anesc.sbq.org.br/online/qnesc06/historia.pdf. Acesso em 05 jan. 2022.

\begin{tabular}{llllll}
\hline Hygeia & Uberlândia - MG & Edição especial: X GeoSaude & Fev./2022 & p. 136-154 Página 152
\end{tabular}


GUIMARÃES, R.B. Saúde: fundamentos de Geografia Humana. São Paulo - SP: Editora UNESP, 2015, 109p. Disponível em: https://static.scielo.org/scielobooks/4xpyq/pdf/quimaraes-

9788568334386.pdf. Acesso em 05 jan. 2022.

KUHN, T. A estrutura das revoluções científicas. Tradução de Beatriz Vianna Boeira e Nelson Boeira. 12ed. São Paulo - SP: Perspectiva, 2012, 323p. (Debates, 115).

LACOSTE, Y. A Geografia isso serve, em primeiro lugar, para fazer a guerra. Campinas - SP: Papirus, 1997, 263p.

LAURELL, A.C. A saúde-doença como processo social. Revista Latinoamericana de Salud. México, vol. 2. P. 7-25.

LEAVELL, H.; CLARK, E.G. Medicina preventiva. Tradução de Maria Cecília Ferro Donnangelo, Moisés Goldbaum e Uraci Simões Ramos. São Paulo - SP: McGraw-Hill do Brasil, 1976, 744p.

LIMA, E.S.; PEREIRA, M.P.B. Roteiro de campo aplicado à Geografia da Saúde e disciplinas afins: percursos em Campina Grande - PB. Campina Grande - PB: 2016. 15p (relatório PIVIC/ UFCG).

LIMA, E.S.; PEREIRA, M.P.B. Trabalho de campo aplicado à Geografia da Saúde e disciplinas afins: locais de visita em Campina Grande - PB. In: PEREIRA, Martha Priscila Bezerra; MAGALHÃES, Sandra Célia Muniz (org.). Perspectivas geográficas da saúde humana. Campina Grande - PB: EDUFCG, 2018, 167p, P. 69-84. PDF. Disponível em: https:// editora.ufcg.edu.br/components/com booklibrary/ebooks/90D44400-F086-ECB4-03396779732AAD21 ff2fac b3589350eb02485296ccda14d90dcf5b.pdf. Acesso em 20 de abril de 2021.

LIMA, S.C.; SANTOS, F.O. Promoção da saúde e redes comunitárias para construção de territórios saudáveis. Uberlândia - MG: EdUFU, 2018, 176p.

MAGALHÃES, S.C.M.; PEREIRA, M.P.B. Pesquisa e extensão em Geografia da Saúde: entre a teoria e a prática. Montes Claros - MG: Editora UNIMONTES, 2017, 251p.

MARCONI, M.A.; LAKATOS, E.M. Fundamentos de metodologia científica. 7.ed. São Paulo - SP: Atlas, 2010, 289p.

MARTINS, P.H.; FONTES, B. Construindo o conceito de redes de vigilância em saúde. In: Redes sociais e saúde: novas possibilidades teóricas. Recife - PE: EDUFPE, 2004, 159p. P. 103-120.

NAUGLE, D.K. Cosmovisão: a história de um conceito. Tradução de Marcelo Heberts. Brasília - DF: Monergismo, 2017, 488p.

PAVLOVSKY, Y.N. Human diseases with natural foci. Moscow: Foreign Languages Publishing House, 1960, 346p.

PEREIRA, E.H.X.; PEREIRA, M.P.B. Situação do Grupo de Pesquisa em Geografia para Promoção da Saúde em relação aos grupos de pesquisa em Geografia e saúde no Brasil. Campina Grande - PB: 2020. 23p. (relatório PIVIC/ UFCG).

PEREIRA, G.S. As expedições científicas e o conhecimento no Brasil. Boletim Geográfico. São Paulo - SP: Editorial do mês. Novembro de 1943, n.8.

PEREIRA, M.P.B. Trabalho de campo na Geografia: desafios práticos e teóricos no estado da Paraíba. In: SILVA, Anieres Barbosa da; GUTIERRES, Henrique Elias Pessoa; GALVÃO, Josias de Castro (org.). Paraíba: pluralidade e representações geográficas. Campina Grande - PB: EDUFCG, 2017, 227p. P. 209-221, PDF. Disponível em: https://4a85131a-e81f-4037-875a-

4c013c98a63c.filesusr.com/ugd/e4bfdf 121c3ab1c07e44799bb0eba6df40c561e.pdf. Acesso em 25 de abril de 2021.

POPPER, K. A lógica da pesquisa científica. São Paulo - SP: Cultrix, 2013, 454p.

PRÓ-SAÚDE GEO. Quem somos? Campina Grande - PB, 2021. Disponível em: www.prosaudegeo.com.br. Acesso em 20 de maio de 2021.

RECUERO, R.C. Comunidades virtuais em redes sociais na internet: uma proposta de estudo.

Revista da Associação dos Programas de Pós-graduação em Comunicação - COMPÓS, p. 127, dezembro de 2005. Disponível em: www.compos.com.br/e-compos. Acesso em 07 de junho de 2019.

Hygeia Uberlândia - MG $\quad$ Edição especial: X GeoSaude $\quad$ Fev./2022 p. 136-154 Página 153


ROUQUAYROL, M.Z.; GURGEL, M. Rouquayrol: epidemiologia e saúde. 7.ed. Rio de Janeiro - RJ: Medbook, 2013, 736p.

SANTOS, G.M.S.; PEREIRA, M.P.B. Teorias aplicáveis à Geografia da saúde: uma revisão da literatura. Campina Grande - PB: 2017. 17p. (relatório PIVIC/ UFCG).

SANTOS, J.P.; STEINKE, V.A.; OLIVEIRA, S.V.; GARCIA-ZAPATA, M.T.A. Espaço e doença: mudanças antrópicas e a hantavirose. Revista Brasileira de Geografia Médica e da Saúde Hygeia v. 12, n. 22, p. 62-71.

SANTOS, M. A natureza do espaço: técnica e tempo, razão e emoção. 2.ed. São Paulo - SP: Hucitec, 1997, 273p.

SEARLE, J.R. Intencionalidade. Tradução de Júlio Fischer e Tomás Rosa Bueno. 2.ed. São Paulo SP: Martins Fontes, 2002. (Coleção tópicos).

SEVERINO, A.J. Metodologia do trabalho científico. 24 ed. São Paulo - SP: Cortex, 2016, 307p.

SILVA, A.B. Conhecimento geográfico aplicado aos roteiros de campo em Geografia da Saúde no município de Campina Grande - PB e municípios circunvizinhos. 2014. Monografia (graduação em Geografia) - Unidade Acadêmica de Geografia, Centro de Humanidades, Universidade Federal de Campina Grande, Campina Grande, 2014, 48 f. Disponível em: https://www.prosaudegeo.com.br/tcc. Acesso em 06 jan. 2022.

SILVA, A.B.; PEREIRA, M.P.B. Conhecimento geográfico aplicado aos roteiros de campo em Geografia da Saúde no município de Campina Grande- PB e municípios circunvizinhos. Campina Grande - PB: 2014. 16p (relatório PIBIC/ CNPq/UFCG).

SILVA, A.B.; PEREIRA, M.P.B. Roteiros de campo em Geografia da Saúde no município de Campina Grande - PB e municípios circunvizinhos. Hygeia, vol. 11, n. 21, p. 20-34, Dez/ 2015. Disponível em: http://www.seer.ufu.br/index.php/hygeia/article/view/30116/17593. Acesso em 20 de abril de 2021.

SILVA, J.E.C.; LIMA, A.B. Trajetórias epistemológicas da geografia: uma análise do conceito de território nos estudos agrários. Campina Grande - PB: 2020. 20p. (relatório PIBIC/ CNPq/UFCG).

SILVA, L.C. O conceito de espaço na epidemiologia das doenças infecciosas. Cadernos de Saúde Pública, Rio de Janeiro - RJ, vol. 13, n. 4, p. 585-593, out-dez, 1997. https://doi.org/10.1590/S0102$\underline{311 X 1997000400002}$

SIRE, J.W. O universo ao lado: um catálogo básico sobre cosmovisão. 5.ed. Tradução de Marcelo Heberts. Brasília - DF: Editora Monergismo, 2018, 318p.

SORRE, M. Fundamentos biológicos de la Geografía Humana: ensayo de uma ecologia del hombre. Traducción revisada por el autor. Barcelona: Editorial Juventud, S.A. 1955, 344p.

SOUZA, M.S.C.; PEREIRA, M.P.B. Desafios e potencialidades do trabalho de campo nos cursos de Geografia em Instituições de Ensino Superior no Brasil. Campina Grande - PB: 2015, 15p (relatório PIVIC/ UFCG).

SOUZA, M.L. A prisão e a ágora. Rio de Janeiro - RJ: Bertrand Brasil, 2006, 632p.

SOUZA, M.L. Os conceitos fundamentais da pesquisa sócio-espacial. 2.ed. Rio de Janeiro - RJ: Bertrand Brasil, 2015, 319p.

TORTORA, G.J.; FUNKE, B.R.; CASE, C.L. Microbiologia. 12.ed. Porto Alegre - RS: Artmed, 2017, 964p.

XAVIER, P.P.S; PEREIRA, M.P.B. Desafios e potencialidades do trabalho de campo nos cursos de Geografia das instituições de Ensino Superior da Paraíba. Campina Grande - PB: 2013, 20p (relatório PIVIC/ UFCG). 